Review Article,

\title{
A Review on Potential of Robotic Rehabilitation in Health Care System
}

\author{
Meena Gupta ${ }^{1}$, Ruchika Kalra ${ }^{2}$ \\ ${ }^{1,2}$ Amity Institute Of Physiotherapy, Amity University Noida, Up, India \\ Email Adress: kalraruchika123@gmail.com
}

\begin{abstract}
:
Robotic rehabilitation states as the restorative therapy for the which act as the augmented tool for the health care workers. The methodology was to collect the articles from various scholar sites and where the scrutinization for 180 articles were done. Where the need of the study was to create review upon the robotic technology in the health care. They act as the rehabilitative tool for the upper and lower limb which is further classified into endoskeletons and exoskeletons which is having which is having different mechanism of play and different outcome. The need of rehabilitation technology with robots is inclusive of accurate monitoring, surgery, medicine and rehabilitation. There is a history of robotics in health care as begin in 1960's for surgery and in 1990's for rehabilitation and now have expanded in various accessible new technologies that are affordable, having multiple control system with various degrees of freedom and different approach to work. Some of them are highly versatile even can work without any supervision. The need of robotics will increase so as to assist not to remove and gain satisfaction at every end of patient and health worker.

The past to present to the future have been very challenging but are present with great outcomes.
\end{abstract}

Keywords: Endoskeleton, exoskeleton, rehabilitation, Robots

\section{Introduction:}

Robotics in rehabilitation is defined as the assisted, augmented tool for clinician and for the patient it works as the restorative therapy and ability to increase the ability to function well beyond the neuro-restoration capability. The concept of robotization present as novel role in the health care system allowing various functions varying from diagnosis, communication, visualization and rehabilitation. The rehabilitation is to control the further complications and decreasing upcoming difficulties and dependency, hence it is required with four step method inclusive of assessment to goals setting by therapist to intervention provided by therapist to reassessment. These steps nowadays are followed with the help of robots which came to be successful than traditional therapy, it provided constant training and mechanism present with it providing feedback for the improvement in the impairment ,and changes according to the feedback given by the patient and therapist hence providing the safety and easy acceptance by the patient and the concerned rehabilitation team.

\section{Methodology:}

The need to study the article was to study the valuation of the robotic rehabilitation in the health care sectors as upcoming dependency of the humans on robots in the day today work life so the analysis arises whether the robots can be an addition to health care society and be a part of every team member in the rehabilitation team. The study was scrutinized by 180 articles to create a review study where the articles are from 1991 to 2019. The study material was from google scholars, pub med, research gate and science direct where the key words were rehabilitation, exoskeleton, endoskeleton and robot. Type of selection for scrutinizing were abstracts, full text, reviews, systematic reviews and randomized control trail. 


\section{Robotic Devices for Rehabilitation:}

1. Exoskeletons robotic devices: These are also known as the powered exoskeletons which are easily wearable robotic device that are controlled by hydraulics, motor, lever devices. these are most commonly found in for the spinal cord injury rehabilitation to restore gait. these robotic exoskeletons contain mechanical structures having sensors, actuators, controlling strategies and have the function to execute the motor function. Its best part is that it controls the] best interaction among human and device which is further classified into two as the cognitive human robot interaction also termed as cHRI which play a role as how the user controls the device and other physical human robot interaction also known as pHRI relating with the applied control forces in between the human and exoskeleton. In exoskeleton the user had to face three steps that is the sense, decision and execution. - cHRI gathers the kinetic information with the sensor technology of the sensors, potentiometers, encoder, accelorometer, gyroscopes, strain gage, piezoresistive sensors, force torques sensors. - pHRI gathers activity of muscle function data, brain data, ocular motion data having sensory technology as electromyography, electroencephalography, and electro-oculargraphy respectively. Nowadays the design of exoskeleton that were followed are for upper extremity using the hard association, adding the passivity to the extremity parts and making the arm 4-6 times heavier, requiring the nonphysiological invariable muscle strategies in ongoing movement. These ideas are utilized to decrease the inertia of the exoskeleton so that joints are away from motor and work with the joints by utilizing cables and pulley. Examples such as CADEN-7, MEDARM. , , CAREX a novel robotic exoskeleton from upper limb which is 10 times lighter. In upper limb the features by robotic exoskeleton were to assist the need of force to make sure that the upper limb follows within the path of required path of the motion and also termed as the path assistance so as to provide higher accuracy in the motion, and the second feature is that to adjust the weight support so as to remove effect of the gravity leading to assistance of motor learning and removing motor synergies in case of partial weight bearing. , ,

In case of lower limb the features are such as by providing the DOF by system of robot which is proficient to perceive the deficiencies in the pattern of gait and the robotic device indirectly applies the forces to train the affected ankles an example such as ankle bot and thus improving balance and gait , There is the other device which provides eight DOF named as LOPES, which is outlined to work for gait rehabilitation and as the passive measurement device. Robotic exoskeletons also decrease the sitting time, encouraging in increase of the walking time leading to increase in the social activities and good quality of life., Robotic exoskeleton are maximally used in spinal cord rehabilitation, as commercially available for different level of spinal cord injury. , Robotic exoskeletons have the problem of energy efficiency so as to accelerate and decelerate, as the device require higher amount of energy to up come the function for dynamically support the weight against gravity. Nowadays lithium batteries are used to to use for these devices. ,

\section{End effector robotic devices:}

End effector robots are $\mathrm{n}$ contact with the patients on one distal joint, the joint of end effector robots are completely distinct from the human joints. The isolated movement in joint is difficult as the interface in distal is altering the position of further joints due leading to force generated causing, difficult in single joint motion. , End effector in the limb of upper extremity is present at hand, and in case for gait training the device is placed at the foot. Manipulandum is the connection between the robotic device and the arm, it is used as the sensors so as to measure the performance. The best part is it is easily fitted to any body type by minimum modification to the device; hence it is advantageous to the upper and lower extremity. In this device the joints cannot be independently adjusted due to interaction of the device is at the single joint surface. MIT- Manus is the most effective of end effector device, as the manipalandum leading to movement in hand placed at the surface of horizontal position and giving, play at direction in vertical due to springs present, this provides the sensorimotor training which is gathered by the manipalandum and can be treated as video games. The goals ate achieved with the help of screen through interaction by the manipalandum helping to draw out the shapes and moving in the path, allowing to complete the work with the assistance with the robot and provides better results than conventional therapy and generating better outcomes, With the help of manipalandum the results are reliable and are used for the recovery measures in the patients due to 
correct kinematic data obtained by the robot. There are also the presence of the passive end effector robots providing to train the arms better and distinctly, and in mirror symmetrical paired manner too. ,, End effector robots give better results in lower extremity due to less complexity as compared to upper limb as present with complexity at distal part. The gait training from end effector robotic device is highly beneficial with positive outcome., The Haptic Walker is an example of end effector robot which stimulate the stair climbing, locomotion training, as present with the force and torques sensors providing an interaction between control strategy, the data is collected and progress according to the output. There is the similar device as of the end effector named as the G-EO- system, which according to clinical study provided the positive outcomes in the control group, presenting with gait control, locomotion training and stair climbing, minimum effort by physiotherapist and decrease risk of fall.

\section{Robotic Devices In The Market :}

\section{Robotic devices for upper limb:}

A. In motion device providing 3degrees of freedom at the wrist a mounted robot present at planar tip.

B. MIT manus a device providing 5 degrees of freedom to wrist, elbow and shoulder.

C. Movement with mirror image enhancer providing 5DOF an completely specified for elbow and shoulder and can be used as bilateral training.

D. Bi-Manu track providing 1 degree of freedom specially for wrist extension and flexion, forearm pronation and supination

E. Arm robot Armin semi-skeleton for upper limb motion providing their degrees of freedom respectively, and present with audiovisual display.

F. Neuro rehabilitation robot having 3-degree s of freedom, framed on direct drive wire actuation providing patients feedback and easily transportable

G. Rehabrob therapeutic system providing the passive shoulder and elbow movements, and providing all the safety measures against it.

H. Gentle/S providing the 3 degrees of freedom having robotic manipulator and gimbal mechanism combining with the forearm and wrist movements together.

\section{Robotic devices for lower limb:}

A. Treadmill based exoskeleton devices consisting of the Lokomat, Loko help ,Alex , Lopes , KAFO, AAFO consisting of the motor drive, treadmill drive, Series elastic actuator as the driving modes providing, passive, active, active assisted as training mode and controlled by the force control, impedance control, trajectory, position and posture control as the control strategies.

B. Leg orthoses exoskeleton robots these are consisting of the HAL, BLEEX , , Rutgers ankle having motor, hydraulic and pneumatic drive respectively as driving mode which provides active assisted, active, active resisted and passive motions.

C. Platform based end effector robots such as ARBOT , , parallel ankle robots, , gait trainer, GTI and the driving mode is motor, providing all motions from passive to active with based on trajectory, EMG evaluation and position control as control strategies.

D. Foot plate based end effector robots such as Haptic walker, Geo system and worked on motor drive followed on the passive, active, active assisted, active, motions and the controlled by trajectory, position control. 


\section{Procedure for Robotic Rehabilitation:}
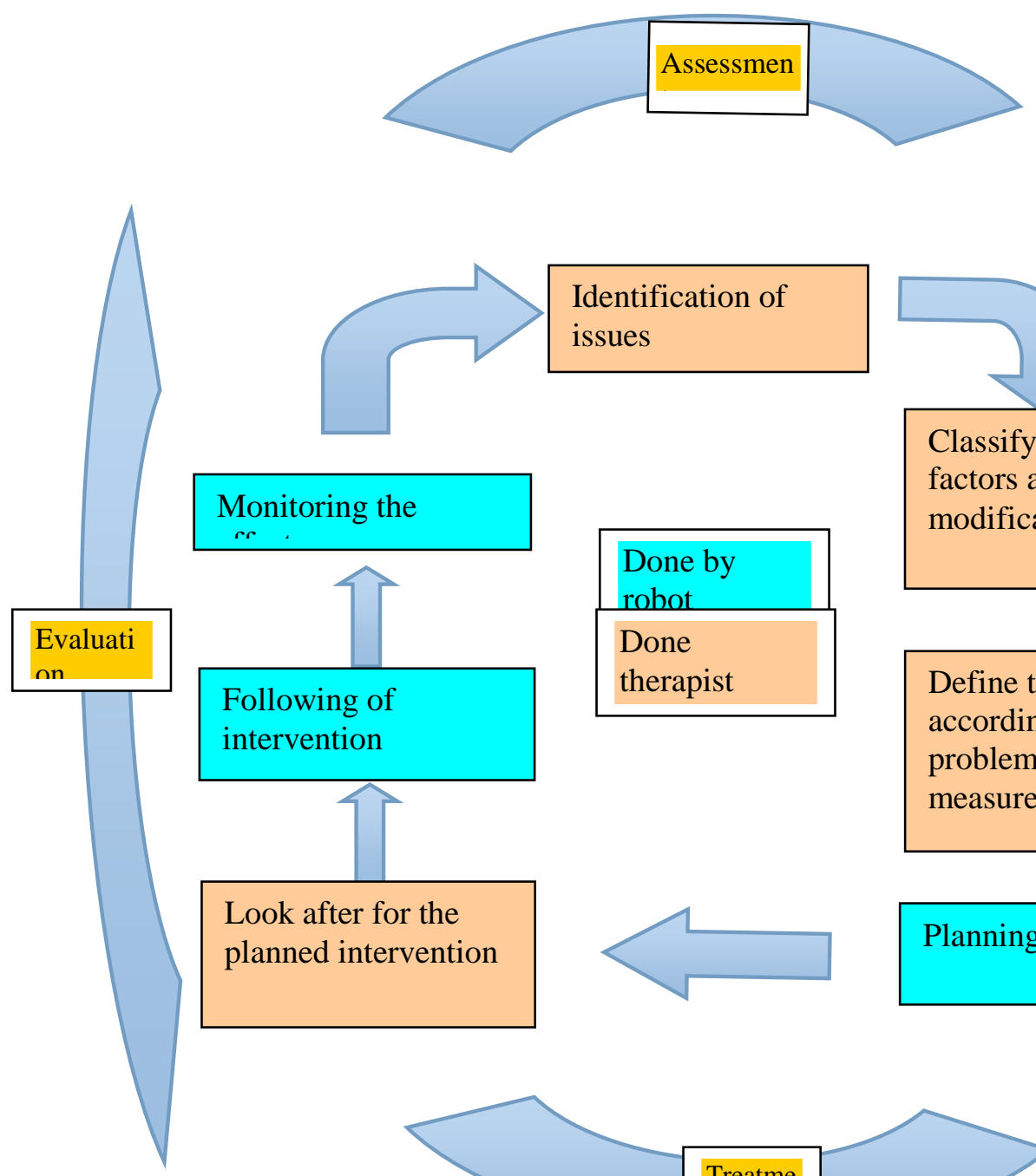

$$
\begin{aligned}
& \text { Fig1. Robotic } \\
& \text { Rehabilitatio } \\
& \text { n system }
\end{aligned}
$$

\section{ROBOTIC REHABILITATION SYSTEM}

\section{Algorithim}

\section{Exoskeleton for upper limb}

The exoskeletons robots are easily wearable device which is automated and is surround to the articulated structures of the upper limb ad worked upon the kinematics for upper extremity and arm of robot is articulated with, powered motors allowing the degrees of freedom with the joint sensors. 


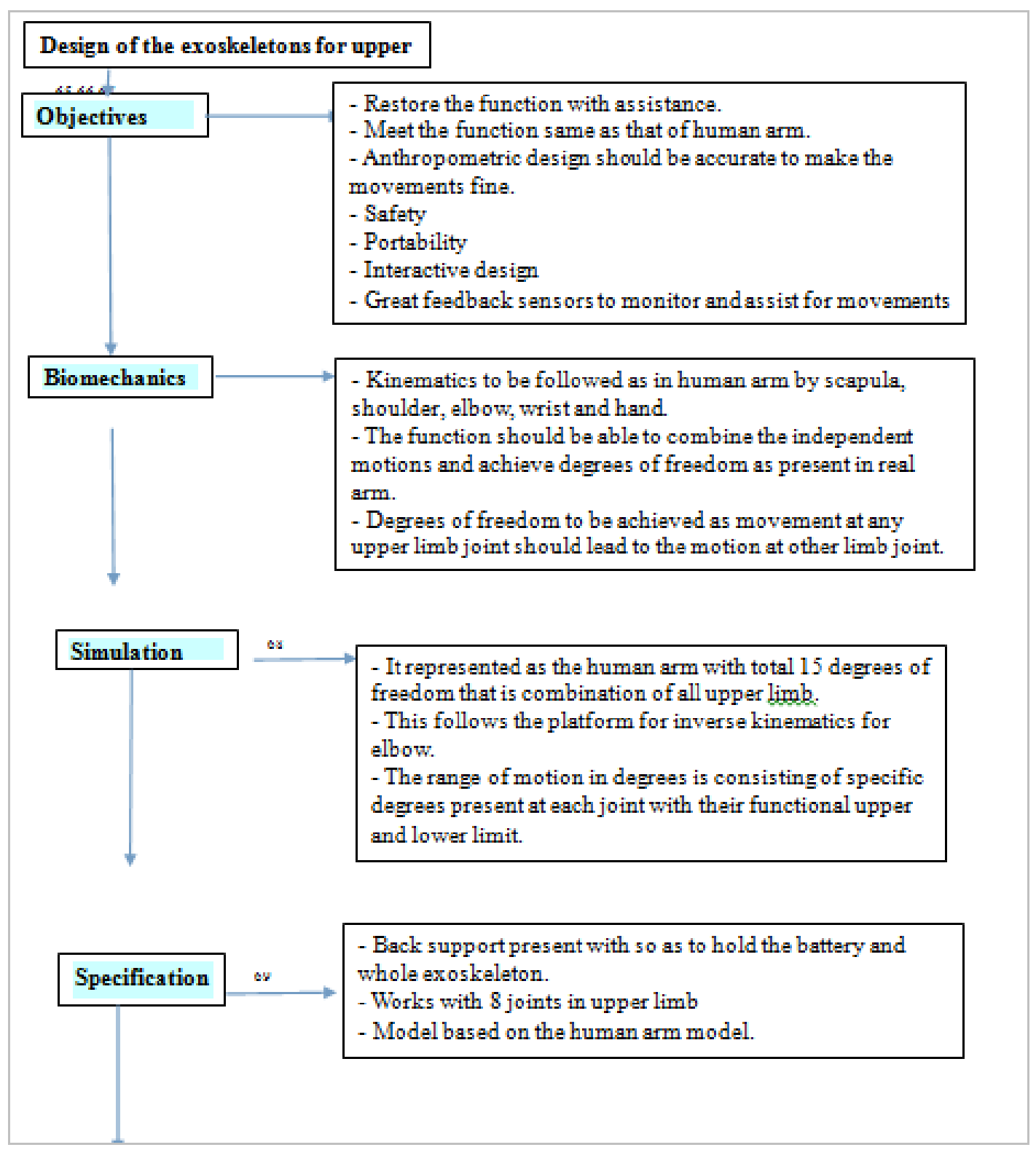



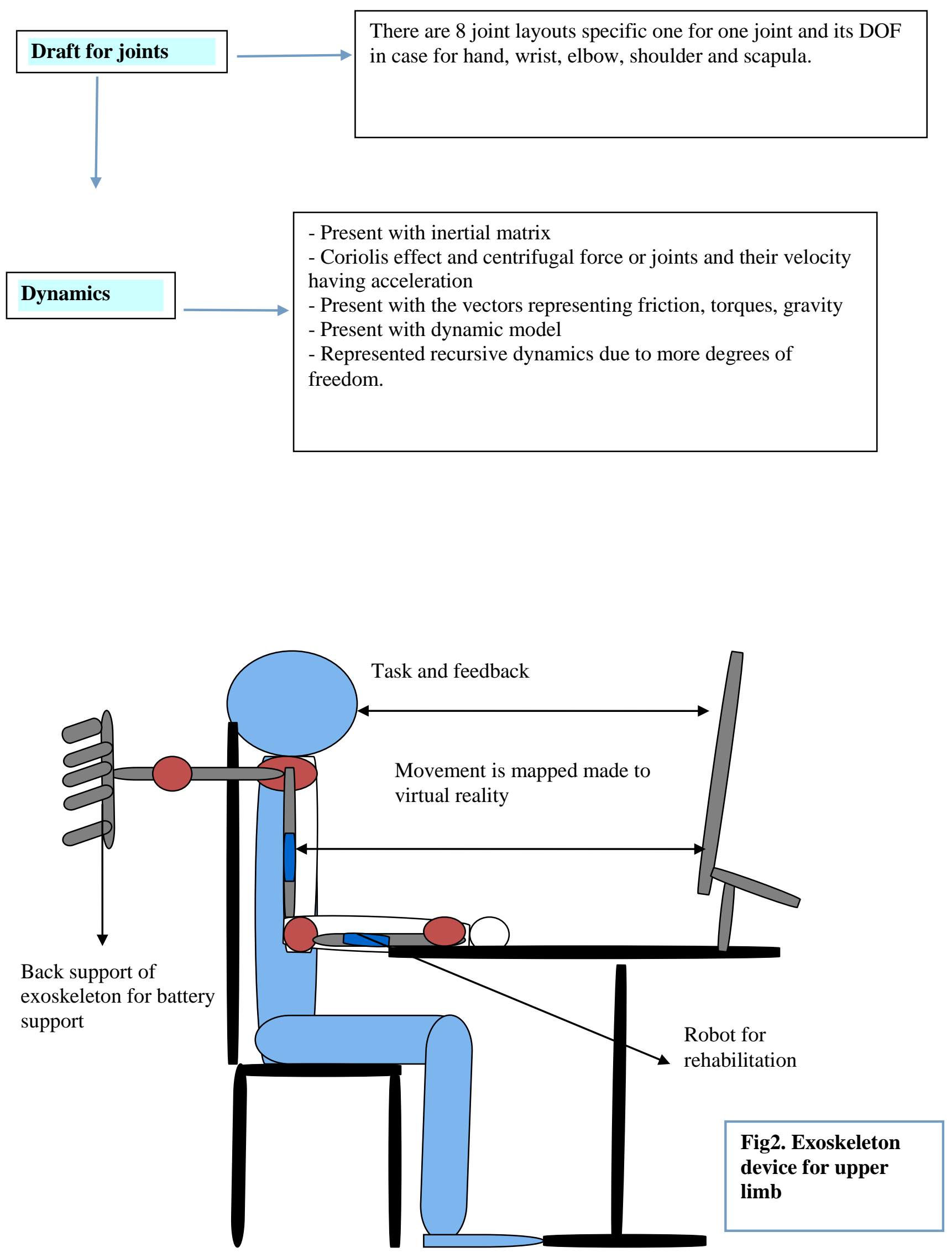


\section{End effector for upper limb:}
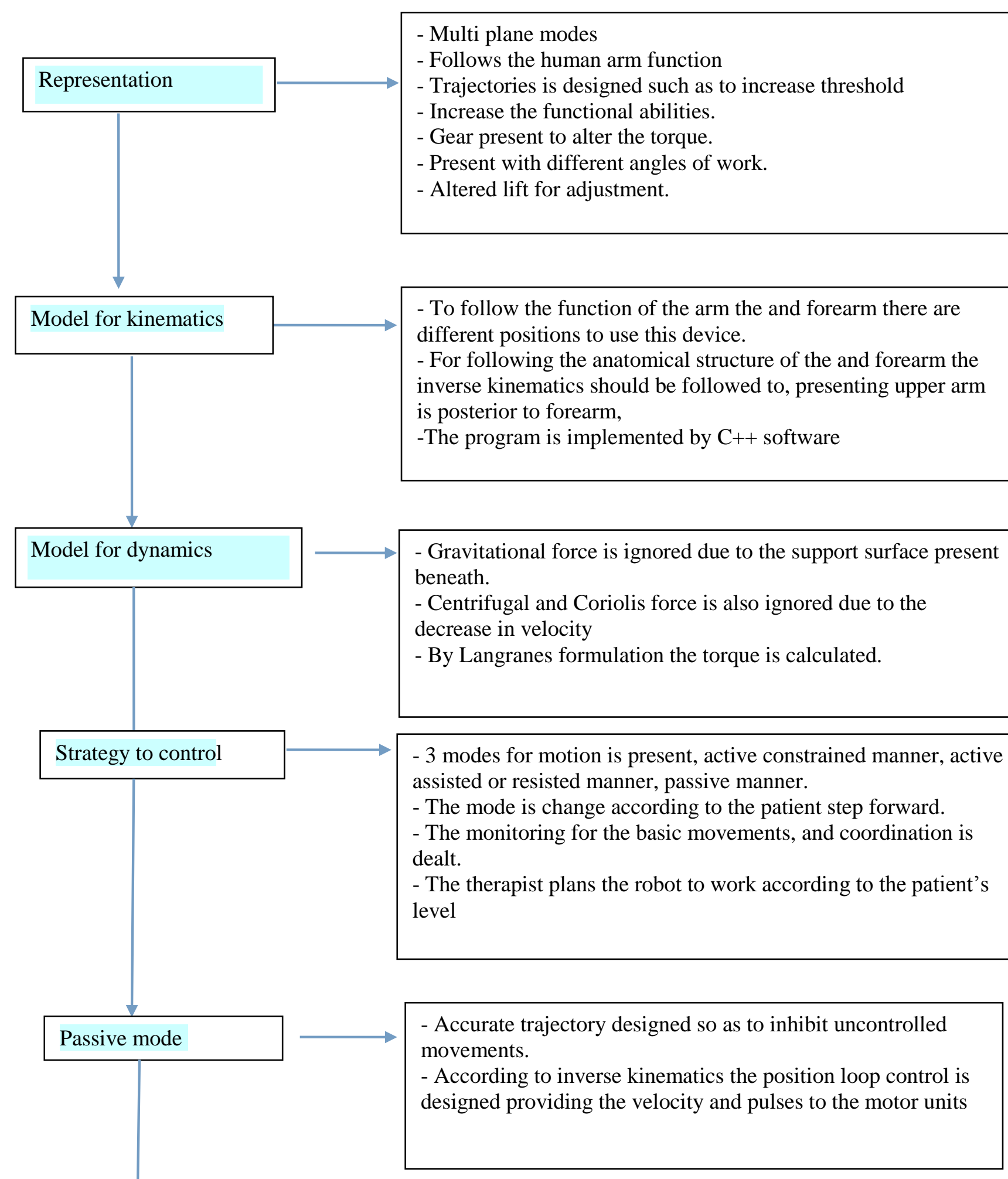


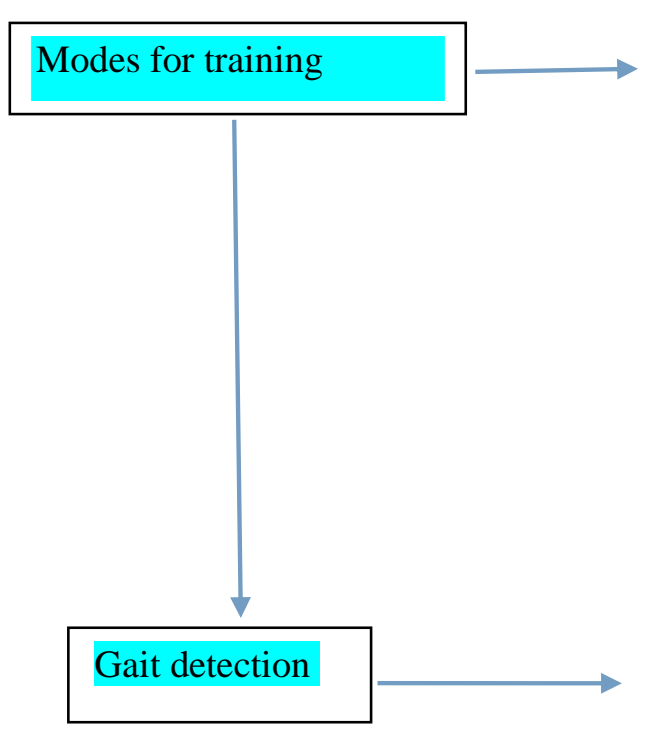

- Passive - in this the patient is monitored through trajectory and rehabilitated with the help of robot's limb so as to achieve passive strength

- Active-In this when the patient present with the volunteer from the movement the robot automatically changes trajectory according to feedback.

-Active assisted - in this the robot assist the patient's limb to work when patient start to achieve then the signal is arrived where the robot tries to lower the assistance and make patient independent.

-Active resisted-In this the limb of the robot is moving opposite to patient's limb so as to make the exercise more useful

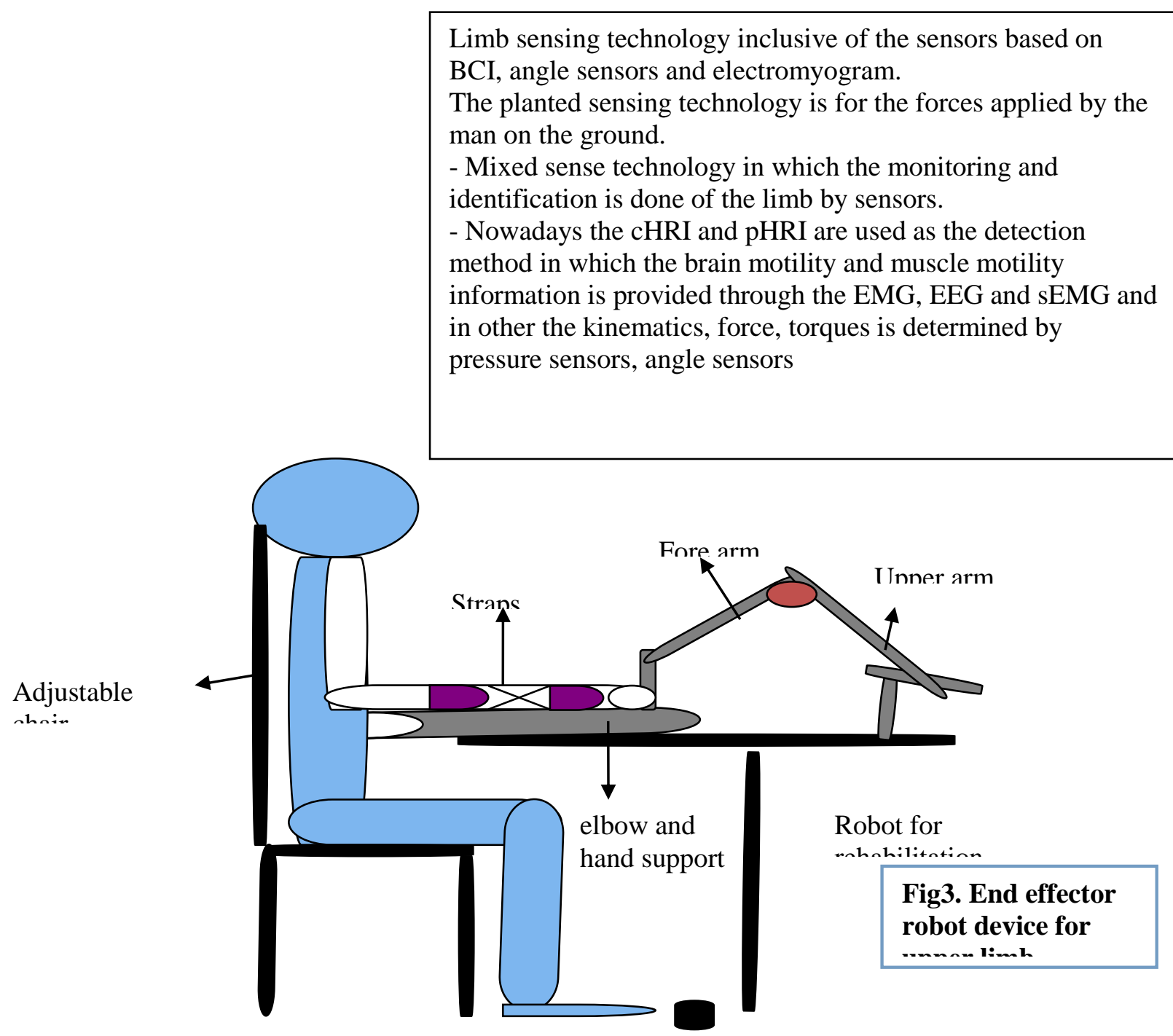




\section{Robotics for lower limb:}

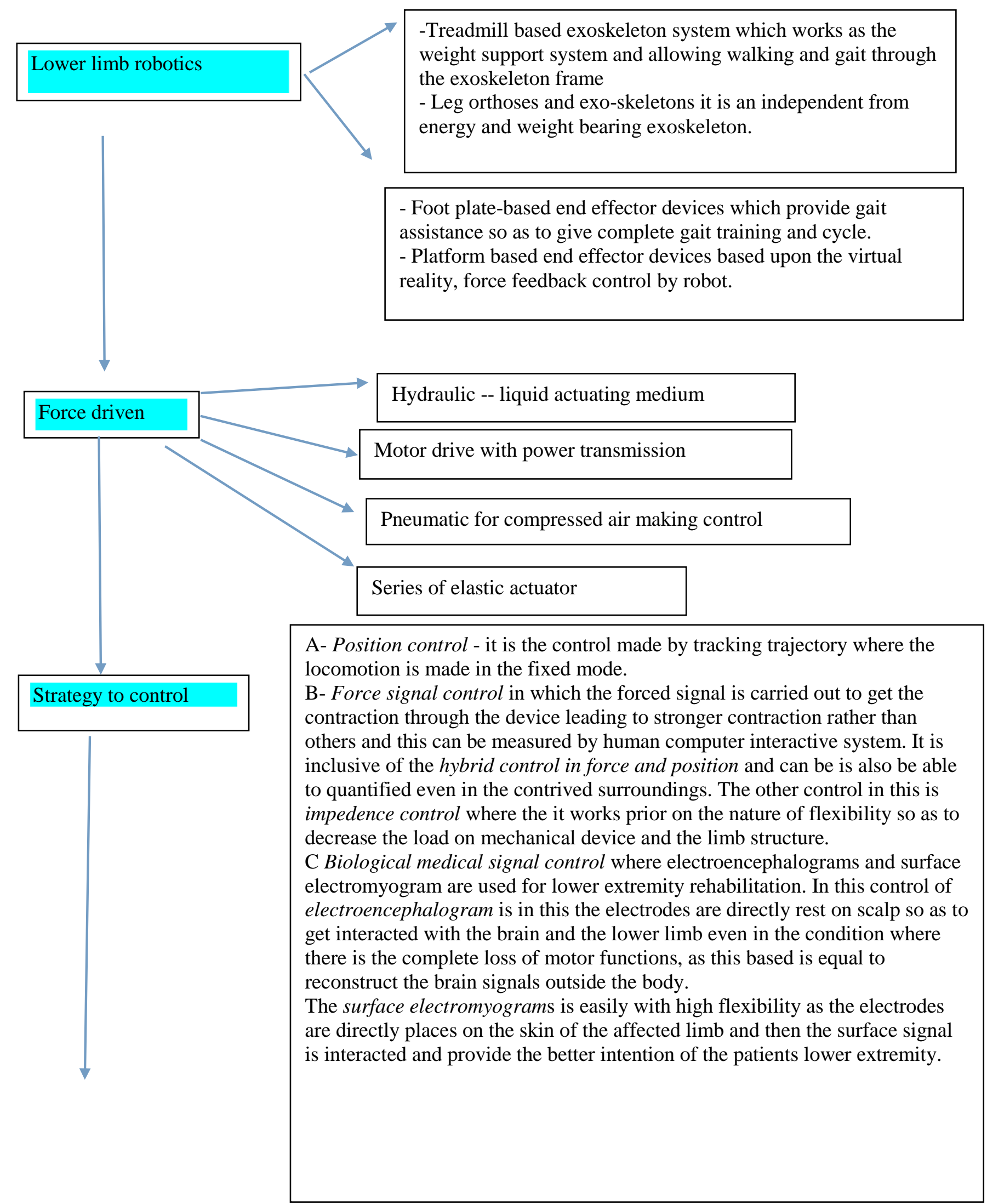



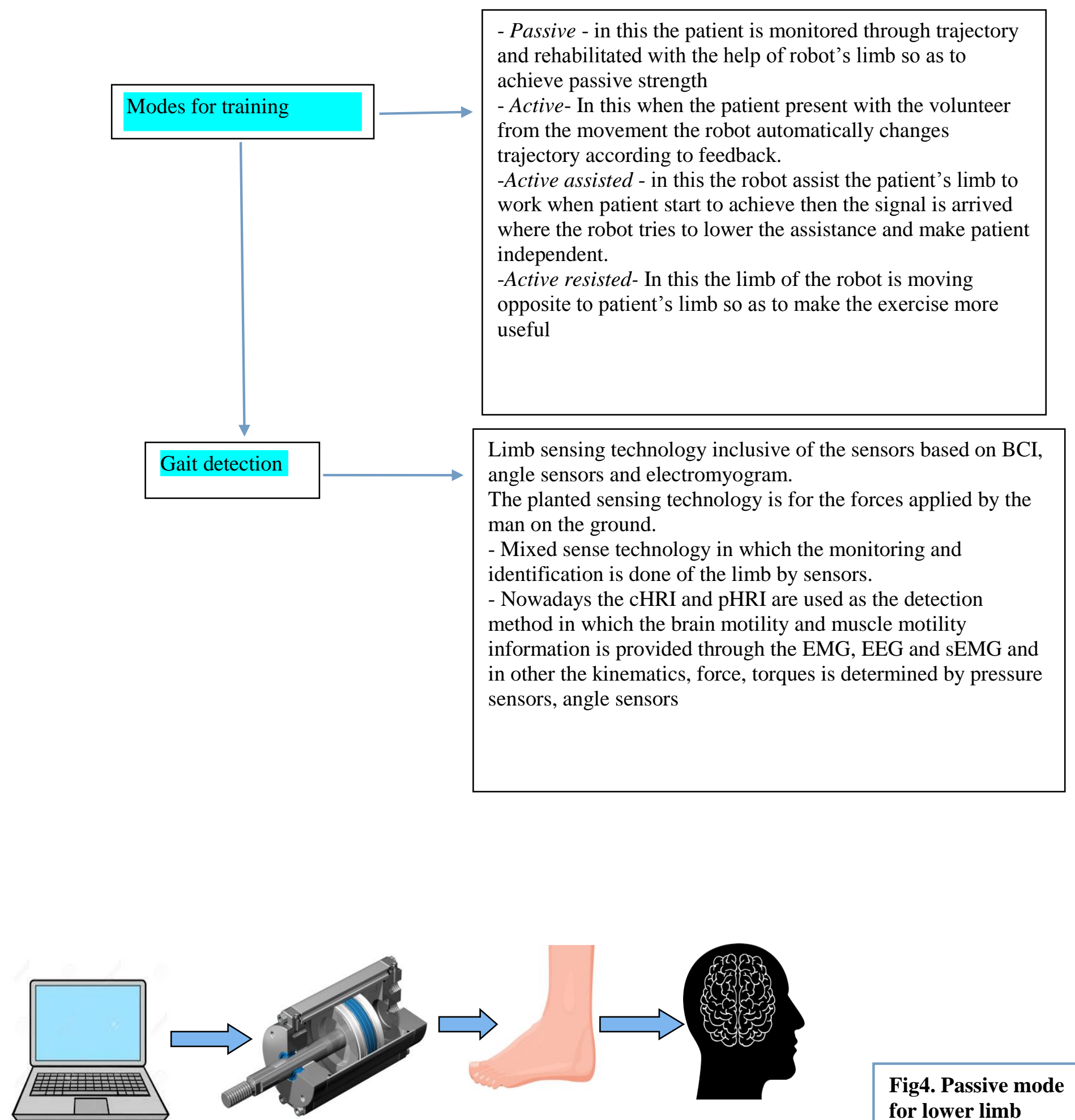
Fig4. Passive mode for lower limb

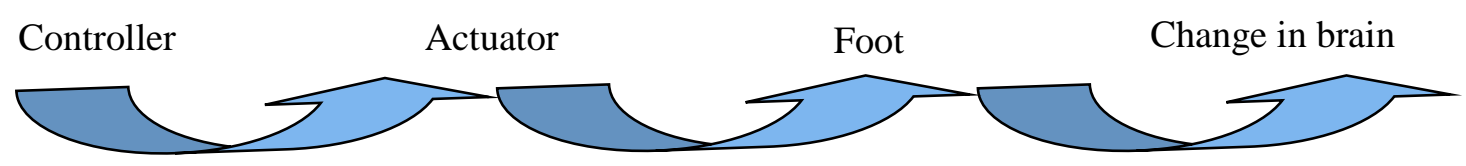

Exercise plan trigeering actuator
Passive movement of foot

\section{PASSIVE MODE}

Occurrence of somatosensory afferences 


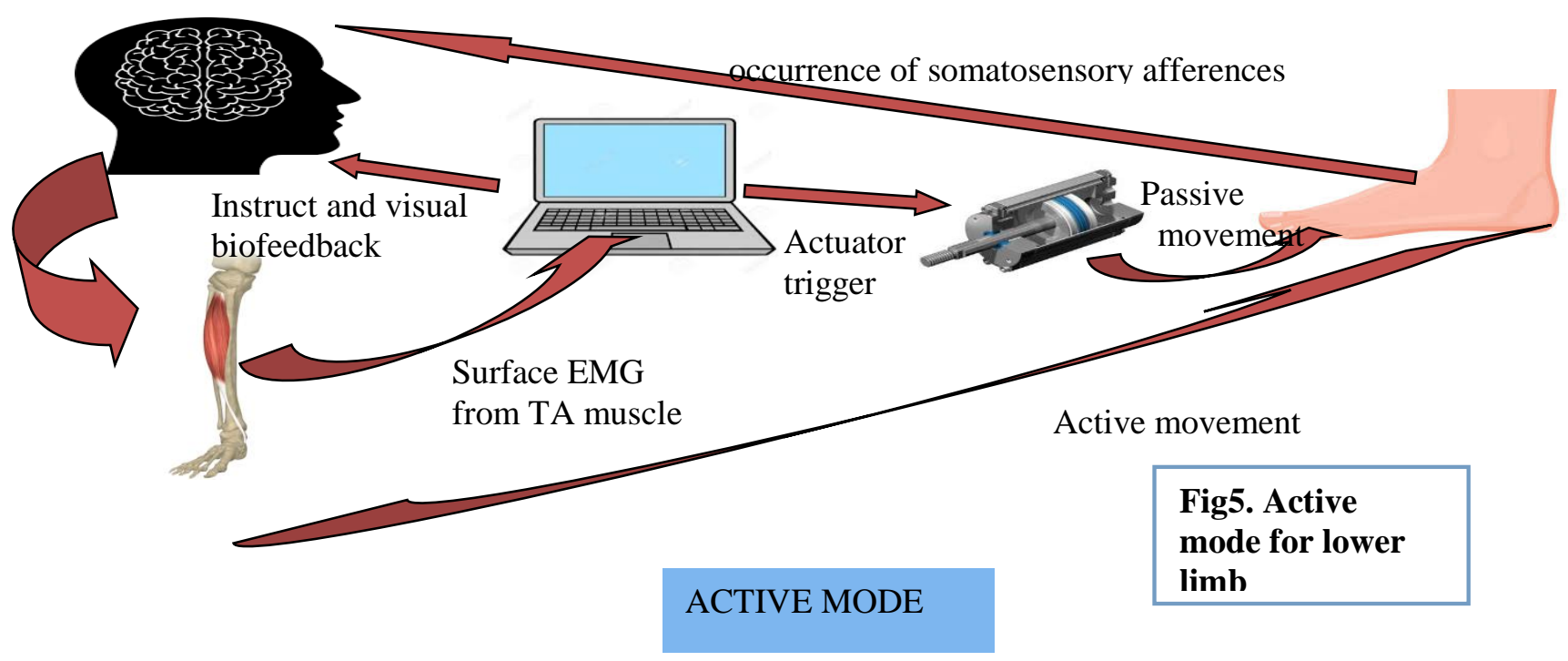

\section{Need For Robotic:}

\section{Rehabilitation}

According to the facts by the WHO statistically drawn out with 70 percent of neurological problems are reported that are progressive and chronic and higher in elder population, whereas the remaining are with amputation, musculo-skeletal disability, pain, traumatic injury, learning disabilities.

The requirement of the automated technology is present with atypical requirements by gathering the alternative mechanism which can restore the function of the disability, and deal with compensation dealt with that disability, the procedure can be followed with wearable technology such as orthosis or even with the electromechanical approach. , problems are reported that are progressive and chronic and higher in elder population, whereas the remaining are with amputation, musculo-skeletal disability, pain, traumatic injury, learning disabilities.

The requirement of the automated technology is present with atypical requirements by gathering the alternative mechanism which can restore the function of the disability, and deal with compensation dealt with that disability, the procedure can be followed with wearable technology such as orthosis or even with the electromechanical approach. ,

According to the studies, drawn that robot-based rehabilitation supports clinicians, for better results in short span of time, these studies are from global perspective, which studies the role of robots in rehabilitation and consider rehabilitation system as the integrated approach . Various studies suggested that nowadays there are various classification of the automated technology in health care, working on various control strategies, and user interface such as EMG and EEG , , basis and focuses on better feedback.

Robotic technology as the brain is dynamic and the property named as plasticity is the fundamental, the plasticity occurs after being aided by the therapy leading to relearning the and make the therapy in more functional. The robotic therapy aids and enhances the plasticity. Due to interaction with the robotic device the therapist is able to interact both with the physical and mental parameters for patients.

\section{Robotics in Health Care:}

Robot institute of America in 1979 framed the termed for robotics as a reconfigurable, versatile, operator which is drafted to mobilize the segments, materials, tools and other particularize task given and configured accordingly.

Medical robots have been specified according to the domain such as surgical, medical and rehabilitation and following the basic science such as tele surgery, ergonomics, DOF, kinematics of motion with different kinds of robots behind. , , , 


\section{IN SURGERY:}

\section{Neurological:}

Neuro-surgery is a very delicate surgery involving precision and accuracy at every step, this can be done under fine medical images, , , it began with computed tomography and stereotactic frame, the biopsy was done by the trajectory of the robot and the probe was placed accordingly. Nowadays the integrated surgical systems involving the image guide positioning, there is the addition of deep brain stimulation and intra cranial stimulation, radio surgery, neuroendoscopy, providing the accuracy for the results where, as the robots are guide the instruments and, somewhere the robot is so small that it can easily be invasive and be useful for review as well as deformity correction, 3D verification can be done easily with ongoing surgery and biopsy. , . Presently the evidence was resulting in better benefits in percutaneous implants in spine assistance.

\section{Orthopaedics:}

Robotic technology is highly beneficial in the surgery for total hip and knee replacements since 1996 , , The root has the accuracy to cut down the bones and re-sect in the clean manner and place the implant with great accuracy and leading to functional outcomes. According to the study the "Orthodoc" was given the name for surgical planner for milling in the bone and plant the implant at that place. The robot in this technology is present with the sensors for safety monitoring covering all the axes and provide better orientation and position. There were many examples such as CASPAR, iblock, Navio PFS, Stanmore sculpture.

, ,

\section{Laparoscopy:}

Robotic technology in the laparoscopy is the surgery for incisions in the abdomen, as there is the placement of visceral organs and decrease visibility at the surgical site the camera used to be inserted as the small modifications in 1980s, this procedure is very difficult as due to less exposure the bigger the incision used to be done as the upcoming technology decreased it further with the help of accuracy and confinement. , ,

Da-vinci a surgical robot for laparoscopy which is installed with multiple functions in it, present with 2 degrees of freedom of wrist, with ease in suturing, surgical mapping, better surgeon ergonomics. The da vinci is installed in four models till now in worldwide as standard, S, Si, Sie ,. These models were enhanced year by year with better vision, easy working, better outcome, besides Sie, Si have the ability to practice surgery in virtual environment.

The other robots were like free hand, Tele- AP, and SOFAR. With different accessibility, endoscopic view and other different parameters such as assistance, manipulators and sensors .

\section{Percutaneous:}

This involves use of needles and suture, drainage, destruction of tumor, delivery of drug, biopsy . The intra operating imaging was used for the surgery with 3-dimensional view, involving MRI compatibility with the joint sensation. The robotic arm is designed and operated with CT scan MRI. ,

\section{Catheters:}

Catherterization is useful as the diagnostic tool in case of vascular injury and its diagnosis in the blood vessels that are obstructed and fluoroscopy is done for the guidance. The steered catheters are the provision to decrease the risk of physician towards radiation., ,

Sensei the robot for steered catheter which handled by the doctor by 3D joystick with the mechanism of pulleys, the sensations are gathered by the vibration at surgeon's hand.

Niobe a robot came with the magnetic technology using the magnets guides catheter for the movement, surgeon can orient the magnetic power fro retraction and the movement inside with change in the magnetic field as required.

\section{In Rehabilitation:}

\section{Prosthetics and orthotics}

These are controlled with the help of exoskeletons, end effector device which are actually a microprocessor device adjusting the dynamics of the device according to the available kinematics in the limb. Examples such as $\mathrm{C}$ leg used for the dynamics of the gait training, they deal with the better functional outcome as powered control on every digit, as the power is made by the remaining limb present by myoelectric signals. , Re walk is the dynamic wheel chair allowing the patient to walk and the stand on their own.

\section{Assistive mobility devices;}

These are the devices which focuses on the wholebody system so as to complete the task for the activities of daily living . Example MIT MANUS a device used for re-educate the patient in all aspect, 
have different function to access, to make patient independent. The signals are produced that provide the feedback to the therapist and the patient. This system records the velocity and the force of motion. The other robot is the Master II which is inclusive of manual, external powered or the pre synchronized motions.

\section{Robots for communication;}

There are robots present specially for the interaction with social environment and improve the psychological aspects, improving the communication skills specially in case of children. In this the feedback is gathered from patient's movement for understanding such as head nodding, the interaction is meant to be in different languages so as to create barrier free environment. These robots are followed in home and hospital settings from mental rehabilitation. These are humanoid robots followed post-surgery or the children in the sterile room such as in case of immuno- compromised condition these robots help them to interact and talk. The examples are: Nao humanoid robot. ,

\section{Motivational robot:}

The researches have been done eliciting that for better rehabilitation one must have better quality of life, hence there are motivational robots deal with your mental state and react optimistically and permits some intellectual tasks such as memory, and other motivational lectures to improvise the QOL.

\section{Advancement within robotic health care}

There are currently many researches going on present with decrease complexity and increased accuracy in various departments that is surgery, medicine, and rehabilitation and many more.

1. Trauma pod it is the semiautonomous telerobotic system for surgery, this system allows the surgery with all the care that is nursing, anesthetics, dressing, monitoring, closing, shunt placement without a single person in theater.

2. In vivo robots are based on da vinci rules of robots and established further where there is a nerbekas laparoscopic surgery system where the arms of the robot are present with 6 degrees of freedom providing the better accuracy with minimum incision.

3. Swallowable capsules and its further evolution developed, that is to be swallowed and it has the sensors controlled by magnetic field fives the imaging without battery, induces electrical peristalsis, provides the help for the ultrasound imaging and biopsy, $\mathrm{pH}$ regulator, bowel movements monitoring, gastric secretions monitoring and more.

4. Heart lander, it is the robot system specially to suction the removal from heart wall, epicardium, pericardium and drug delivery and other cardiac procedures with minimum incision.

5. MrBot and Neuro arm: Mrbot is the device with pneumatic steeper motors to reduce the MR interference which provides a access to prostate gland and with horizontal linkage arm for magnetic resonance imaging entrance. The neuro arm works with 3 DOF with micrometers and sensors for optics working with MRI access with piezoelectric motors.

6. Microsurgery and RAVEN: RAVEN A device for teleoperated laparoscopic surgery present with 7 degrees of freedom each in both arms which works on kinematic spherical mechanism with adjustable length and angles of arms for function in the arm. The device is less expensive a light in weight. Whereas the Microsurgery is for endoscopic surgery, providing highly versatile functions with different domain of surgery.

7. Amaedeus: a laparoscopic surgery device for complete of intutive design of da vinci robotic system, this robot provides high level of flexibility and as present with snake arms. from long distance surgery as tele operative.

\section{Discussion:}

The robotic technology for the health care system is wide based system which provides a wide featured are inclusive of all the facilities, where the technology plays the role in increase of assistance for the procedures that are difficult to procure, but this does not lead to any removal of health care workers.

Robotic based rehabilitation is very useful for faster and accurate results in part of rehabilitation where the routine management can be done with accurate monitoring after every session and feedback is provided both to therapist and patient, commercially available robots are high on demand and are present in out-patient rehabilitation and deals with number of patients.

In robotics in rehabilitation patient is prescribed with the accurate regimen prescribed by therapist ,to be followed under the supervision of therapist, this provides the better outcome and increased 
amount of gratification. ,

Most commonly with the patients with low level of motivations tends not to comply with the intervention hence the robot is induced with addition of motivation as supplement with the intervention to improve the outcome. This was induced with the help of gaming with exercise and for getting engaged the children with concentration and better amount of the results. ,

In earlier rehabilitation with robotics were with decrease amount of interaction which now been improved in all senses such as feedback sensors, visual auditory, haptic and performance cues, motivation and virtual reality for better interaction.

After lots of research the robotic mechanism developed with the comfortable chair attached with the controller of computer that is managed by therapist and the patient is attached with orthosis and haptic device which is suspended and are moved according to the result required and the visual and haptic feedback is obtained and the treatment effect is quantified. ,

The great challenge was to introduce gaming in the rehabilitation process to made to process faster and interactive with entertainment specially in case of sensory deficits. The gaming provide the level of difficulty same throughout the rehabilitation. The gaming is structured according to the steps which provides feedback of the patient with desirable mood and undesirable mood and its movements and helps to encourage simultaneously., , ,

There was new technology named ARMin exoskeleton rehabilitation robots provided the virtual games such as hockey, tennis and the mods can be changed according to patients mood and this therapy intensifies rehabilitation.

The senior and geriatric population is present with more amount of age-related disability, where the robotic technology helps by indulging social aspects, solving intellectual questions with lots of motivation beside which gathers the better amount of therapy and improvement. There are competitions assigned for cognitive skills and set according level of understanding and interest. The haptic joysticks play a role in cognitive development such as by planning virtual situation of polluted cities and to analyze the images and the data. There is one device Novint Falcon a low haptic device provides the force feedback and the position of end effector and able to differentiate between patients with disabilities and the patient under stroke intervention rehabilitation.
The rehabilitation exercises are very useful to recover, and also can be followed at home easily but the feedback, accuracy and intensity of exercise to be quantified, which is now possible with the help of home based rehabilitation robots, which are there in the market at low cost and affordable in case of Novint Falcon and java therapy but with a issue limited to small movements. Hence the Microsoft Kinect is new in technology where the motion is tracked with the help of camera allowing the estimation for all the sides of motions in 3 dimensions. This kinect is not only combined with the gaming but also with computer for its versatility making custom interface and better rehabilitation. , ,

\section{Conclusion:}

The robotic technology in the health care is a widely based system having the ability to transform the health care sector into new base with the accuracy in every department such as medicine, surgery, rehabilitation, and social. The robotic technology provides the long term rehabilitation and most accurate in cost effectiveness, time of recovery, feedback, this is guaranteed to be fulfilled. Due to this the robotic technology have come up with less time of surgery, fast recovery, less dependency, emergency care, nursing care, and rehabilitation which is easily accessible to the health care sectors and there team.

\section{Referance:}

[1] Krebs HA, Volpe BT. Rehabilitation robotics. Handbook of clinical neurology. 2013 Jan 1;110:283-94.

[2] Stollnberger G, Moser C, Beck E, Zenz C, Tscheligi M, Szczesniak-Stanczyk D, Janowski M, Brzozowski W, Blaszczyk R, Mazur M, Wysokinski A. Robotic systems in health care. In2014 7th International Conference on Human System Interactions (HSI) 2014 Jun 16 (pp. 276281). IEEE.

[3] Winstein CJ, Stein J, Arena R, Bates B, Cherney LR, Cramer SC, Deruyter F, Eng JJ, Fisher B, Harvey RL, Lang CE. Guidelines for adult stroke rehabilitation and recovery: a guideline for healthcare professionals from the American Heart Association/American Stroke Association. Stroke. 2016 Jun;47(6):e98-169..

[4] Langhorne P, Bernhardt J, Kwakkel G. Stroke care 2. Stroke rehabilitation. Lancet. 2011;377(9778):1693-702. 
[5] Volpe BT, Krebs HI, Hogan N. Is robot-aided sensorimotor training in stroke rehabilitation a realistic option?. Current opinion in neurology. 2001 Dec 1;14(6):74552.doi:10.1097/00019052-200112000-00011

[6] Bosecker C, Dipietro L, Volpe B, Igo Krebs H. Kinematic robot-based evaluation scales and clinical counterparts to measure upper limb motor performance in patients with chronic stroke. Neurorehabilitation and neural repair. 2010 Jan;24(1):62-9.

[7] Krebs HI, Hogan N, Aisen ML, Volpe BT. Robot-Aided[26] MP Ottensmeyer. Telerobotic surgery: Feedback time delay effects on Neurorehabilitation," IEEE Transactions on RehabilitationEngineering, vol. task assignement," Master's thesis, MIT, Cambridge, MA. 1996;6:75-87.

[8] Dijkers MP, deBear PC, Erlandson RF, Kristy K, Geer DM, Nichols A. Patient and staff acceptance of robotic technology in occupational therapy: a pilot study. J Rehabil Res Dev. 1991 Mar 1;28(2):33-44.

[9] Gorgey AS, Sumrell R, Goetz LL. Exoskeletal assisted rehabilitation after spinal cord injury. InAtlas of Orthoses and Assistive Devices 2019 Jan 1 (pp. 440-447). Content Repository Only!.

[10] Knaepen K, Beyl P, Duerinck S, Hagman F, Lefeber D, Meeusen R. Human-robot interaction: Kinematics and muscle activity inside a powered compliant knee exoskeleton. IEEE transactions on neural systems and rehabilitation engineering. 2014 May 16;22(6):1128-37.

[11] Gopura RA, Bandara DS, Kiguchi K, Mann GK. Developments in hardware systems of active upper-limb exoskeleton robots: A review. Robotics and Autonomous Systems. 2016 Jan 1;75:203-20.

[12] Frisoli A, Rocchi F, Marcheschi S, Dettori A, Salsedo F, Bergamasco M. A new forcefeedback arm exoskeleton for haptic interaction in virtual environments. InFirst Joint Eurohaptics Conference and Symposium on Haptic Interfaces for Virtual Environment and Teleoperator Systems. World Haptics Conference 2005 Mar 18 (pp. 195-201). IEEE.

[13] Perry JC, Rosen J, Burns S. Upper-limb powered exoskeleton design. IEEE/ASME transactions on mechatronics. 2007 Aug 20;12(4):408-17.

[14] Perry JC, Rosen J. Design of a 7 degree-offreedom upper-limb powered exoskeleton. InThe First IEEE/RAS-EMBS International Conference on Biomedical Robotics and Biomechatronics, 2006. BioRob 2006. 2006 Feb 20 (pp. 805-810). IEEE.

[15] Jin X, Aluru V, Raghavan P, Agrawal SK. The effect of CAREX on muscle activation during a point-to-point reaching task. In2015 IEEE International Conference on Rehabilitation Robotics (ICORR) 2015 Aug 11 (pp. 73-78). IEEE.

[16] Runnalls, K. D., Anson, G., Wolf, S. L., \& Byblow, W. D. (2014). Partial weight support differentially affects corticomotor excitability across muscles of the upper limb. Physiological reports, 2(12), e12183.

[17] Sabini RC, Dijkers MP, Raghavan P. Stroke survivors talk while doing: development of a therapeutic framework for continued rehabilitation of hand function post stroke. Journal of Hand Therapy. 2013 Apr 1;26(2):124-31..

[18] Sabini RC, Dijkers MP, Raghavan P. Stroke survivors talk while doing: development of a therapeutic framework for continued rehabilitation of hand function post stroke. Journal of Hand Therapy. 2013 Apr $1 ; 26(2): 124-31$.

[19] Roy A, Krebs HI, Barton JE, Macko RF, Forrester LW. Anklebot-assisted locomotor training after stroke: A novel deficit-adjusted control approach. In2013 IEEE International Conference on Robotics and Automation 2013 May 6 (pp. 2175-2182). IEEE.

[20] Roy A, Krebs HI, Patterson SL, Judkins TN, Khanna I, Forrester LW, Macko RM, Hogan N. Measurement of human ankle stiffness using the anklebot. In2007 IEEE 10th International Conference on Rehabilitation Robotics 2007 Jun 13 (pp. 356-363). IEEE.

[21] Baunsgaard CB, Nissen UV, Brust AK, Frotzler A, Ribeill C, Kalke YB, León N, Gómez B, Samuelsson K, Antepohl W, Holmström U. Gait training after spinal cord injury: safety, feasibility and gait function following 8 weeks of training with the exoskeletons from Ekso Bionics. Spinal cord. 2018 Feb;56(2):106-16.

[22] Gorgey AS, Wade R, Sumrell R, Villadelgado L, Khalil RE, Lavis T. Exoskeleton training may improve level of physical activity after spinal cord injury: a case series. Topics in spinal cord injury rehabilitation. 2017;23(3):245-55.

[23] Gorgey AS, Sumrell R, Goetz LL. Exoskeletal assisted rehabilitation after spinal cord injury. InAtlas of Orthoses and Assistive Devices 2019 Jan 1 (pp. 440-447). Content Repository Only!.

[24] Gorgey AS, Wade R, Sumrell R, Villadelgado L, Khalil RE, Lavis T. Exoskeleton training may improve level of physical activity after spinal cord injury: a case series. Topics in spinal cord injury rehabilitation. 2017;23(3):245-55. 
[25] Ruiz-Olaya AF, Burgos CA, Londoño LT. A Low-Cost Arm Robotic Platform based on Myoelectric Control for Rehabilitation Engineering. In2019 IEEE 10th Annual Ubiquitous Computing, Electronics \& Mobile Communication Conference (UEMCON) 2019 Oct 10 (pp. 0929-0933). IEEE.

[26] Belogusev V, Egorov A. Efficiency testing of electric rotary actuators with non-standard reduction units for lower limb exoskeletons. Journal of Applied Engineering Science. 2019;17(4):496-503.

[27] Maciejasz P, Eschweiler J, Gerlach-Hahn K, Jansen-Troy A, Leonhardt S. A survey on robotic devices for upper limb rehabilitation. Journal of neuroengineering and rehabilitation. 2014 Dec 1;11(1):3.

[28] Nordin N, Xie SQ, Wünsche B. Assessment of movement quality in robot-assisted upper limb rehabilitation after stroke: a review. Journal of neuroengineering and rehabilitation. 2014 Dec 1;11(1):137.

[29] Colombo R, Pisano F, Micera S, Mazzone A, Delconte C, Carrozza MC, Dario P, Minuco G. Robotic techniques for upper limb evaluation and rehabilitation of stroke patients. IEEE transactions on neural systems and rehabilitation engineering. 2005 Sep 12;13(3):311-24.

[30] Ferraro M, Palazzolo JJ, Krol J, Krebs HI, Hogan N, Volpe BT. Robot-aided sensorimotor arm training improves outcome in patients with chronic stroke. Neurology. 2003 Dec 9;61(11):1604-7.

[31] Laut J, Porfiri M, Raghavan P. The present and future of robotic technology in rehabilitation. Current physical medicine and rehabilitation reports. 2016 Dec 1;4(4):312-9.

[32] Ferraro M, Palazzolo JJ, Krol J, Krebs HI, Hogan N, Volpe BT. Robot-aided sensorimotor arm training improves outcome in patients with chronic stroke. Neurology. 2003 Dec 9;61(11):1604-7.

[33] Fasoli SE, Krebs HI, Stein J, Frontera WR, Hogan N. Effects of robotic therapy on motor impairment and recovery in chronic stroke. Archives of physical medicine and rehabilitation. 2003 Apr 1;84(4):477-82.

[34] Krebs HI, Hogan N, Aisen ML, Volpe BT. Robot-aided neurorehabilitation. IEEE transactions on rehabilitation engineering. 1998 Mar;6(1):75-87.

[35] Luft AR, McCombe-Waller S, Whitall J, Forrester LW, Macko R, Sorkin JD, Schulz JB, Goldberg AP, Hanley DF. Repetitive bilateral arm training and motor cortex activation in chronic stroke: a randomized controlled trial. Jama. 2004 Oct 20;292(15):1853-61.
[36] Whitall J, Waller SM, Silver KH, Macko RF. Repetitive bilateral arm training with rhythmic auditory cueing improves motor function in chronic hemiparetic stroke. Stroke. 2000 Oct;31(10):2390-5.

[37] Stoykov ME, Stinear JW. Active-passive bilateral therapy as a priming mechanism for individuals in the subacute phase of post-stroke recovery: a feasibility study. American journal of physical medicine \& rehabilitation/Association of Academic Physiatrists. 2010 Nov;89(11):873.

[38] Laut J, Porfiri M, Raghavan P. The present and future of robotic technology in rehabilitation. Current physical medicine and rehabilitation reports. 2016 Dec 1;4(4):312-9.

[39] Byblow WD, Stinear CM, Smith MC, Bjerre L, Flaskager BK, McCambridge AB. Mirror symmetric bimanual movement priming can increase corticomotor excitability and enhance motor learning. PloS one. 2012 Mar 22;7(3):e33882.

[40] Mehrholz J, Pohl M. Electromechanicalassisted gait training after stroke: a systematic review comparing end-effector and exoskeleton devices. Journal of rehabilitation medicine. 2012 Mar 5;44(3):193-9.

[41] Low KH. Recent development and trends of clinical-based gait rehabilitation robots. InIntelligent Assistive Robots 2015 (pp. 41-75). Springer, Cham.

[42] Schmidt H, Hesse S, Bernhardt R, Krüger J. HapticWalker---a novel haptic foot device. ACM Transactions on Applied Perception (TAP). 2005 Apr 1;2(2):166-80..

[43] Hesse S, Waldner A, Tomelleri C. Innovative gait robot for the repetitive practice of floor walking and stair climbing up and down in stroke patients. Journal of neuroengineering and rehabilitation. 2010 Dec 1;7(1):30.

[44] Hesse S, Tomelleri C, Bardeleben A, Werner C, Waldner A. Robot-assisted practice of gait and stair climbing in nonambulatory stroke patients. J Rehabil Res Dev. 2012 Apr 1;49(4):613-22.

[45] Poli P, Morone G, Rosati G, Masiero S. Robotic technologies and rehabilitation: new tools for stroke patients' therapy. BioMed Research International. 2013 Jan 1;2013.

[46] Barroso F, Santos C, Moreno JC. Influence of the robotic exoskeleton Lokomat on the control of human gait: An electromyographic and kinematic analysis. In2013 IEEE 3rd Portuguese Meeting in Bioengineering (ENBENG) 2013 Feb 20 (pp. 1-6). IEEE.

[47] Freivogel S, Mehrholz J, Husak-Sotomayor T, Schmalohr D. Gait training with the newly developed 'LokoHelp'-system is feasible for 
non-ambulatory patients after stroke, spinal cord and brain injury. A feasibility study. Brain Injury. 2008 Jan 1;22(7-8):625-32.

[48] Banala SK, Kim SH, Agrawal SK, Scholz JP. Robot assisted gait training with active leg exoskeleton (ALEX). IEEE transactions on neural systems and rehabilitation engineering. 2008 Oct 31;17(1):2-8.

[49] Vladareanu L, Melinte O, Bruja A, Wang H, Wang X, Cang S, Yu H, Hou ZG, Xie XL. Haptic interfaces for the rescue walking robots motion in the disaster areas. In2014 UKACC International Conference on Control (CONTROL) 2014 Jul 9 (pp. 498-503). IEEE.

[50] Blaya JA, Herr H. Adaptive control of a variable-impedance ankle-foot orthosis to assist drop-foot gait. IEEE Transactions on neural systems and rehabilitation engineering. 2004 Mar 15;12(1):24-31.

[51] Sawicki GS, Ferris DP. A pneumatically powered knee-ankle-foot orthosis (KAFO) with myoelectric activation and inhibition. Journal of neuroengineering and rehabilitation. $2009 \mathrm{Dec}$ $1 ; 6(1): 23$

[52] Sawicki GS, Ferris DP. A pneumatically powered knee-ankle-foot orthosis (KAFO) with myoelectric activation and inhibition. Journal of neuroengineering and rehabilitation. 2009 Dec $1 ; 6(1): 23$.

[53] Song S, Zhang X, Li Q, Fang H, Ye Q, Tan Z. Dynamic Analysis and Design of Lower Extremity Power-Assisted Exoskeleton. InWearable Sensors and Robots 2017 (pp. 145164). Springer, Singapore.

[54] Zoss AB, Kazerooni H, Chu A. Biomechanical design of the Berkeley lower extremity exoskeleton (BLEEX). IEEE/ASME Transactions on mechatronics. $2006 \mathrm{Apr}$ 10;11(2):128-38.

[55] Girone M, Burdea G, Bouzit M, Popescu V, Deutsch JE. A Stewart platform-based system for ankle telerehabilitation. Autonomous robots. 2001 Mar 1;10(2):203-12.

[56] Saglia JA, Tsagarakis NG, Dai JS, Caldwell DG. A high-performance redundantly actuated parallel mechanism for ankle rehabilitation. The International Journal of Robotics Research. 2009 Sep;28(9):1216-27.

[57] Saglia JA, Tsagarakis NG, Dai JS, Caldwell DG. Control strategies for patient-assisted training using the ankle rehabilitation robot (ARBOT). IEEE/ASME Transactions on Mechatronics. 2012 Sep 6;18(6):1799-808.

[58] Tsoi YH, Xie SQ, Mallinson GD. Joint force control of parallel robot for ankle rehabilitation. In2009 IEEE international conference on control and automation 2009 Dec 9 (pp. 18561861). IEEE.
[59] 'Tsoi YH, Xie SQ, Mallinson GD. Joint force control of parallel robot for ankle rehabilitation. In2009 IEEE international conference on control and automation 2009 Dec 9 (pp. 18561861). IEEE.

[60] Schmidt H, Werner C, Bernhardt R, Hesse S, Krüger J. Gait rehabilitation machines based on programmable footplates. Journal of neuroengineering and rehabilitation. 2007 Dec;4(1):1-7.

[61] Agrawal SK, Herder J. An approach called" complementary limb motion estimation" was implemented on the" LOPES" gait rehabilitation robot.

[62] Hesse S, Tomelleri C, Bardeleben A, Werner C, Waldner A. Robot-assisted practice of gait and stair climbing in nonambulatory stroke patients. J Rehabil Res Dev. 2012 Apr 1;49(4):613-22.

[63] Ona ED, Cano-de La Cuerda R, SánchezHerrera P, Balaguer C, Jardón A. A review of robotics in neurorehabilitation: Towards an automated process for upper limb. Journal of healthcare engineering. 2018 Apr 1;2018.

[64] Milot MH, Spencer SJ, Chan V, Allington JP, Klein J, Chou C, Bobrow JE, Cramer SC, Reinkensmeyer DJ. A crossover pilot study evaluating the functional outcomes of two different types of robotic movement training in chronic stroke survivors using the arm exoskeleton BONES. Journal of neuroengineering and rehabilitation. 2013 Dec $1 ; 10(1): 112$.

[65] Nordin N, Xie SQ, Wünsche B. Assessment of movement quality in robot-assisted upper limb rehabilitation after stroke: a review. Journal of neuroengineering and rehabilitation. $2014 \mathrm{Dec}$ 1;11(1):137.

[66] Menychtas D, Carey SL, Dubey R. Simulation algorithm for the upper limb for better training and prosthesis prescription for amputees. InProceedings of the 8th ACM International Conference on PErvasive Technologies Related to Assistive Environments 2015 Jul 1 (pp. 1-6).

[67] Pons JL. Rehabilitation exoskeletal robotics. IEEE Engineering in Medicine and Biology Magazine. 2010 May 27;29(3):57-63.

[68] Delp SL, Anderson FC, Arnold AS, Loan P, Habib A, John CT, Guendelman E, Thelen DG. OpenSim: open-source software to create and analyze dynamic simulations of movement. IEEE transactions on biomedical engineering. 2007 Oct 22;54(11):1940-50.

[69] Holzbaur KR, Murray WM, Delp SL. A model of the upper extremity for simulating musculoskeletal surgery and analyzing neuromuscular control. Annals of biomedical engineering. 2005 Jun 1;33(6):829-40.

[70] Liu Y, Li C, Ji L, Bi S, Zhang X, Huo J, Ji R. 
Development and implementation of an endeffector upper limb rehabilitation robot for hemiplegic patients with line and circle tracking training. Journal of Healthcare Engineering. 2017 Jun 15;2017.

[71] Aprile I, Rabuffetti M, Padua L, Di Sipio E, Simbolotti C, Ferrarin M. Kinematic analysis of the upper limb motor strategies in stroke patients as a tool towards advanced neurorehabilitation strategies: a preliminary study. BioMed research international. 2014 Mar;2014.

[72] Behnke RS. Kinetic anatomy. Human Kinetics 1; 2006.

[73] Aprile I, Rabuffetti M, Padua L, Di Sipio E, Simbolotti C, Ferrarin M. Kinematic analysis of the upper limb motor strategies in stroke patients as a tool towards advanced neurorehabilitation strategies: a preliminary study. BioMed research international. 2014 Mar;2014.

[74] Vanderniepen I, Van Ham R, Naudet J, Van Damme M, Vanderborght B, Versluys R, Lefeber D. Novel compliant actuator for safe and ergonomic rehabilitation robots-design of a powered elbow orthosis. In2007 IEEE 10th International Conference on Rehabilitation Robotics 2007 Jun 13 (pp. 790-797). IEEE.

[75] Zhang F, Li P, Hou ZG, Lu Z, Chen Y, Li Q, Tan M. sEMG-based continuous estimation of joint angles of human legs by using BP neural network. Neurocomputing. 2012 Feb 15;78(1):139-48.

[76] Riener R, Lünenburger L, Colombo G. Humancentered robotics applied to gait training and assessment. Journal of Rehabilitation Research \& Development. 2006 Aug 1;43(5).

[77] Zhang X, Yue Z, Wang J. Robotics in lowerlimb rehabilitation after stroke. Behavioural neurology. 2017 Jun 8;2017.

[78] Robertson DG, Caldwell GE, Hamill J, Kamen G, Whittlesey S. Research methods in biomechanics. Human kinetics; 2013 Nov 1.

[79] Goffredo M, Bernabucci I, Schmid M, Conforto S. A neural tracking and motor control approach to improve rehabilitation of upper limb movements. Journal of NeuroEngineering and Rehabilitation. 2008 Dec 1;5(1):5.

[80] Duvinage M, Castermans T, Petieau M, Seetharaman K, Hoellinger T, Cheron G, Dutoit T. A subjective assessment of a P300 BCI system for lower-limb rehabilitation purposes. In2012 Annual International Conference of the IEEE Engineering in Medicine and Biology Society 2012 Aug 29 (pp. 3845-3849). IEEE.

[81] Climent JM, Sánchez J. Indicadores de salud y medicina de rehabilitación: estimadores de incapacidad en la población. Rehabilitación.
1996;30:277-86.

[82] Iosa M, Morone G, Cherubini A, Paolucci S. The three laws of neurorobotics: a review on what neurorehabilitation robots should do for patients and clinicians. Journal of medical and biological engineering. 2016 Feb 1;36(1):1-1.

[83] Muradore R, Fiorini P, Akgun G, Barkana DE, Bonfe M, Boriero F, Caprara A, De Rossi G, Dodi R, Elle OJ, Ferraguti F. Development of a cognitive robotic system for simple surgical tasks. International Journal of Advanced Robotic Systems. 2015 Apr 15;12(4):37.

[84] Chua, K.S.G.; Kuah, C.W.K. Innovating With Rehabilitation Technology in the Real World: Promises, Potentials, and Perspectives. Am. J. Phys. Med. Rehabil. 2017, 96, S150-S150.

[85] Van der Loos, H.M.; Reinkensmeyer, D.J.; Guglielmelli, E. Rehabilitation and Health Care Robotics; Springer Handbook of Robotics; Siciliano, B., Khatib, O., Eds.; Springer International Publishing: Cham, Switzerland, 2016; pp. 1685-1728

[86] Lo AC, Guarino PD, Richards LG, Haselkorn JK, Wittenberg GF, Federman DG, Ringer RJ, Wagner TH, Krebs HI, Volpe BT, Bever Jr CT. Robot-assisted therapy for long-term upperlimb impairment after stroke. New England Journal of Medicine. 2010 May 13;362(19):1772-83.

[87] Kwakkel G, Kollen BJ, Krebs HI. Effects of robot-assisted therapy on upper limb recovery after stroke: a systematic review. Neurorehabilitation and neural repair. 2008 Mar;22(2):111-21.

[88] Ona ED, Cano-de La Cuerda R, SánchezHerrera P, Balaguer C, Jardón A. A review of robotics in neurorehabilitation: Towards an automated process for upper limb. Journal of healthcare engineering. 2018 Apr 1;2018.

[89] Marchal-Crespo L, Reinkensmeyer DJ. Review of control strategies for robotic movement training after neurologic injury. Journal of neuroengineering and rehabilitation. 2009 Dec;6(1):1-5.

[90] Yan T, Cempini M, Oddo CM, Vitiello N. Review of assistive strategies in powered lower-limb orthoses and exoskeletons. Robotics and Autonomous Systems. 2015 Feb 1;64:12036.

[91] Bamdad M, Zarshenas H, Auais MA. Application of BCI systems in neurorehabilitation: a scoping review. Disability and Rehabilitation: Assistive Technology. 2015 Sep 3;10(5):355-64.review. Disabil. Rehabil. Assist. Technol. 2015, 10, 355-364

[92] Cervera MA, Soekadar SR, Ushiba J, Millán JD, Liu M, Birbaumer N, Garipelli G. Braincomputer interfaces for post-stroke motor 
rehabilitation: a meta-analysis. Annals of clinical and translational neurology. 2018 May;5(5):651-63.

[93] Li M, Xu G, Xie J, Chen C. A review: Motor rehabilitation after stroke with control based on human intent. Proceedings of the Institution of Mechanical Engineers, Part $\mathrm{H}$ : Journal of Engineering in Medicine. 2018 Apr;232(4):34460.

[94] Huang H, Wolf SL, He J. Recent developments in biofeedback for neuromotor rehabilitation. Journal of neuroengineering and rehabilitation. 2006 Dec 1;3(1):11.

[95] Krebs HI, Hogan N. Robotic therapy: the tipping point. American journal of physical medicine \& rehabilitation/Association of Academic Physiatrists. 2012 Nov;91(11 0 3):S290.

[96] Morone G, Spitoni GF, De Bartolo D, Ghanbari Ghooshchy S, Di Iulio F, Paolucci S, Zoccolotti P, Iosa M. Rehabilitative devices for a topdown approach. Expert review of medical devices. 2019 Mar 4;16(3):187-95.

[97] Ferreira FM, Chaves ME, Oliveira VC, Van Petten AM, Vimieiro CB. Effectiveness of robot therapy on body function and structure in people with limited upper limb function: A systematic review and meta-analysis. PloS one. 2018 Jul 12;13(7):e0200330.

[98] Berkelman P, Troccaz J, Cinquin P. Bodysupported medical robots: a survey. Journal of Robotics and Mechatronics. 2004;16:513-9.

[99] Moustris GP, Hiridis SC, Deliparaschos KM, Konstantinidis KM. Evolution of autonomous and semi-autonomous robotic surgical systems: a review of the literature. The international journal of medical robotics and computer assisted surgery. 2011 Dec;7(4):375-92.

[100] Badaan SR, Stoianovici D. Robotic systems: past, present, and future. InRobotics in genitourinary surgery 2011 (pp. 655-665). Springer, London.

[101] Guo L, Pan X, Li Q, Zheng F, Bao Z. A survey on the gastrointestinal capsule micro-robot based on wireless and optoelectronic technology. Journal of nanoelectronics and optoelectronics. 2012 Mar 1;7(2):123-7.

[102] Guo L, Pan X, Li Q, Zheng F, Bao Z. A survey on the gastrointestinal capsule micro-robot based on wireless and optoelectronic technology. Journal of nanoelectronics and optoelectronics. 2012 Mar 1;7(2):123-7.

[103] Najarian S, Fallahnezhad M, Afshari E. Advances in medical robotic systems with specific applications in surgery-A review. Journal of medical engineering \& technology. 2011 Jan 1;35(1):19-33.

[104] Nathoo N, Çavuşoğlu MC, Vogelbaum MA,
Barnett GH. In touch with robotics: neurosurgery for the future. Neurosurgery. 2005 Mar 1;56(3):421-33.

[105] Haidegger T, Kovács L, Fordos G, Benyó Z, Kazanzides P. Future trends in robotic neurosurgery. In14th Nordic-Baltic Conference on Biomedical Engineering and Medical Physics 2008 (pp. 229-233). Springer, Berlin, Heidelberg.

[106] Kwoh YS, Hou J, Jonckheere EA, Hayati S. A robot with improved absolute positioning accuracy for CT guided stereotactic brain surgery. IEEE Transactions on Biomedical Engineering. 1988 Feb;35(2):153-60.

[107] Li QH, Zamorano L, Pandya A, Perez R, Gong J, Diaz F. The application accuracy of the NeuroMate robot - a quantitative comparison with frameless and frame-based surgical localization systems. Computer Aided Surgery. 2002 Jan 1;7(2):90-8.

[108] Brodie J, Eljamel S. Evaluation of a neurosurgical robotic system to make accurate burr holes. The International Journal of Medical Robotics and Computer Assisted Surgery. 2011 Mar;7(1):101-6.

[109] Devito DP, Kaplan L, Dietl R, Pfeiffer M, Horne D, Silberstein B, Hardenbrook M, Kiriyanthan G, Barzilay Y, Bruskin A, Sackerer D. Clinical acceptance and accuracy assessment of spinal implants guided with SpineAssist surgical robot: retrospective study. Spine. 2010 Nov 15;35(24):2109-15.

[110] Bargar WL, Bauer A, Börner M. Primary and Revision Total Hip Replacement Using the Robodoc (R) System. Clinical Orthopaedics and Related Research (1976-2007). 1998 Sep 1;354:82-91.

[111] Davies B. A review of robotics in surgery. Proceedings of the Institution of Mechanical Engineers, Part H: Journal of Engineering in Medicine. 2000 Jan 1;214(1):129-40.

[112] Schulz AP, Seide K, Queitsch C, Von Haugwitz A, Meiners J, Kienast B, Tarabolsi M, Kammal M, Jürgens C. Results of total hip replacement using the Robodoc surgical assistant system: clinical outcome and evaluation of complications for 97 procedures. The International Journal of Medical Robotics and Computer Assisted Surgery. 2007 Dec;3(4):301-6.

[113] Kazanzides P, Zuhars JF, Mittelstadt BD, Taylor RH. Force sensing and control for a surgical robot. InICRA 1992 May 12 (pp. 612617)..

[114] Plaskos C, Cinquin P, Lavallée S, Hodgson AJ. Praxiteles: a miniature bone-mounted robot for minimal access total knee arthroplasty. The International Journal of Medical Robotics and 
Computer Assisted Surgery. 2005 Dec;1(4):6779.

[115] Brisson G, Kanade T, DiGioia A, Jaramaz B. Precision freehand sculpting of bone. InInternational Conference on Medical Image Computing and Computer-Assisted Intervention 2004 Sep 26 (pp. 105-112). Springer, Berlin, Heidelberg.

[116] Brisson G. The precision freehand sculptor: A robotic tool for less invasive joint replacement surgery. Carnegie Mellon University; 2008.

[117] Harrell AG, Heniford BT. Minimally invasive abdominal surgery: lux et veritas past, present, and future. The American journal of surgery. 2005 Aug 1;190(2):239-43.

[118] Gomes P. Surgical robotics: Reviewing the past, analysing the present, imagining the future. Robotics and Computer-Integrated Manufacturing. 2011 Apr 1;27(2):261-6.

[119] Dogangil G, Davies BL, Rodriguez y Baena F. A review of medical robotics for minimally invasive soft tissue surgery. Proceedings of the Institution of Mechanical Engineers, Part $\mathrm{H}$ : Journal of Engineering in Medicine. 2010 May 1;224(5):653-79.

[120] Kuo CH, Dai JS. Robotics for minimally invasive surgery: a historical review from the perspective of kinematics. InInternational symposium on history of machines and mechanisms 2009 (pp. 337-354). Springer, Dordrecht.

[121] Mozer P, Troccaz J, Stoianovici D. Robotics in urology: past, present, and future. InAtlas of robotic urologic surgery 2011 (pp. 3-13). Humana Press.

[122] Shah K, Abaza R. Comparison of intraoperative outcomes using the new and old generation da Vinci ${ }^{\circledR}$ robot for robot-assisted laparoscopic prostatectomy. BJU international. 2011 Nov;108(10):1642-5.

[123] Lerner MA, Ayalew M, Peine WJ, Sundaram CP. Does training on a virtual reality robotic simulator improve performance on the da Vinci ${ }^{\circledR}$ surgical system?. Journal of Endourology. 2010 Mar 1;24(3):467-72.

[124] Stark M, Benhidjeb T, Gidaro S, Morales ER. The future of telesurgery: a universal system with haptic sensation. Journal of the Turkish German Gynecological Association. 2012;13(1):74.

[125] DiMaio SP, Salcudean SE. Needle steering and model-based trajectory planning. InInternational Conference on Medical Image Computing and Computer-Assisted Intervention 2003 Nov 15 (pp. 33-40). Springer, Berlin, Heidelberg.

[126] Melzer A, Gutmann B, Remmele T, Wolf R,
Lukoscheck A, Bock M, Bardenheuer H, Fischer $\mathrm{H}$. Innomotion for percutaneous image-guided interventions. IEEE Engineering in Medicine and Biology Magazine. 2008 May 23;27(3):66-73..

[127] Li M, Kapoor A, Mazilu D, Horvath KA. Pneumatic actuated robotic assistant system for aortic valve replacement under MRI guidance. IEEE Transactions on Biomedical Engineering. 2010 Oct 28;58(2):443-51.

[128] Zangos S, Melzer A, Eichler K, Sadighi C, Thalhammer A, Bodelle B, Wolf R, GruberRouh T, Proschek D, Hammerstingl R, Müller C. MR-compatible assistance system for biopsy in a high-field-strength system: initial results in patients with suspicious prostate lesions. Radiology. 2011 Jun;259(3):903-10.

[129] Swan HJ, Ganz W, Forrester J, Marcus H, Diamond G, Chonette D. Catheterization of the heart in man with use of a flow-directed balloon-tipped catheter. New England Journal of Medicine. 1970 Aug 27;283(9):447-51.

[130] Franz MR, Burkhoff D, Spurgeon H, Weisfeldt ML, Lakatta EG. In vitro validation of a new cardiac catheter technique for recording monophasic action potentials. European heart journal. 1986 Jan 1;7(1):34-41.

[131] Steven D, Servatius H, Rostock T, Hoffmann B, Drewitz I, Müllerleile K, Sultan A, Aydin MA, Meinertz T, Willems S. Reduced fluoroscopy during atrial fibrillation ablation: benefits of robotic guided navigation. Journal of cardiovascular electrophysiology. 2010 Jan;21(1):6-12.

[132] Reddy VY, Neuzil P, Malchano ZJ, Vijaykumar R, Cury R, Abbara S, Weichet J, McPherson CD, Ruskin JN. View-synchronized robotic image-guided therapy for atrial fibrillation ablation. Circulation. 2007;115(21):2705-14.

[133] Fu Y, Liu H, Huang W, Wang S, Liang Z. Steerable catheters in minimally invasive vascular surgery. The International Journal of Medical Robotics and Computer Assisted Surgery. 2009 Dec;5(4):381-91.

[134] Riga CV, Bicknell CD, Wallace D, Hamady M, Cheshire N. Robot-assisted antegrade in-situ fenestrated stent grafting. Cardiovascular and interventional radiology. 2009 May 1;32(3):522-4.

[135] Chun JK, Ernst S, Matthews S, Schmidt B, Bansch D, Boczor S, Ujeyl A, Antz M, Ouyang F, Kuck KH. Remote-controlled catheter ablation of accessory pathways: results from the magnetic laboratory. European heart journal. 2007 Jan 1;28(2):190-5.

[136] Leksell L. Stereotactic radiosurgery. Journal of Neurology, Neurosurgery \& Psychiatry. 1983 Sep 1;46(9):797-803.

[137] De Salles AA, Gorgulho A, Agazaryan N, 
Slotman B, Selch M, Burwick AJ, Schulz R, editors. Shaped beam radiosurgery: state of the art. Springer Science \& Business Media; 2011 Mar 23.

[138] Adler Jr JR, Chang SD, Murphy MJ, Doty J, Geis P, Hancock SL. The Cyberknife: a frameless robotic system for radiosurgery. Stereotactic and functional neurosurgery. 1997;69(1-4):124-8.

[139] Gagnon GJ, Nasr NM, Liao JJ, Molzahn I, Marsh D, McRae D, Henderson Sr FC. Treatment of spinal tumors using cyberknife fractionated stereotactic radiosurgery: pain and quality-of-life assessment after treatment in 200 patients. Neurosurgery. 2009 Feb 1;64(2):297307.

[140] Liu A, Agazaryan N, Yu C, Han H, Schultheiss $\mathrm{T}$, Wong J. A multi-center consortium study of competing platforms for intracranial stereotactic irradiation. International Journal of Radiation Oncology• Biology• Physics. 2008 Sep 1;72(1):S213.

[141] Kasina H, Bahubalendruni MR, Botcha R. Robots in medicine: past, present and future. International Journal of Manufacturing, Materials, and Mechanical Engineering (IJMMME). 2017 Oct 1;7(4):44-64.

[142] Halperin HR, Paradis N, Ornato JP, Zviman M, LaCorte J, Lardo A, Kern KB. Cardiopulmonary resuscitation with a novel chest compression device in a porcine model of cardiac arrest: improved hemodynamics and mechanisms. Journal of the American College of Cardiology. 2004 Dec 7;44(11):2214-20.

[143] Hallstrom AL, Rea TD, Sayre MR, Christenson J, Anton AR, Mosesso VN, Van Ottingham L, Olsufka M, Pennington S, White LJ, Yahn S. Manual chest compression vs use of an automated chest compression device during resuscitation following out-of-hospital cardiac arrest: a randomized trial. Jama. 2006 Jun 14;295(22):2620-8.

[144] Palmer RW. Integrated diagnostic and treatment devices for enroute critical care of patients within theater. ARMY MEDICAL RESEARCH AND MATERIEL COMMAND FORT DETRICK MD; 2010 Apr 1.

[145] Frennert SA, Forsberg A, Östlund B. Elderly people's perceptions of a telehealthcare system: Relative advantage, compatibility, complexity and observability. Journal of technology in human services. 2013 Jul 1;31(3):218-37.

[146] Sucher JF, Todd SR, Jones SL, Throckmorton T, Turner KL, Moore FA. Robotic telepresence: a helpful adjunct that is viewed favorably by critically ill surgical patients. The American Journal of Surgery. 2011 Dec 1;202(6):843-7.

[147] Seymour R, Engbretson B, Kott K, Ordway N,
Brooks G, Crannell J, Hickernell E, Wheeler K. Comparison between the C-leg® microprocessor-controlled prosthetic knee and non-microprocessor control prosthetic knees: a preliminary study of energy expenditure, obstacle course performance, and quality of life survey. Prosthetics and orthotics international. 2007 Mar;31(1):51-61.

[148] Low KH. Robot-assisted gait rehabilitation: From exoskeletons to gait systems. In2011 Defense Science Research Conference and Expo (DSR) 2011 Aug 3 (pp. 1-10). IEEE.

[149] Beasley RA. Medical robots: current systems and research directions. Journal of Robotics. 2012 Oct;2012.

[150] Hillman M. Rehabilitation robotics from past to present-a historical perspective. InProceedings of the ICORR 2003 Apr 22 (Vol. 2003, No. 4, pp. 23-25).

[151] Waldner A, Werner C, Hesse S. Robot assisted therapy in neurorehabilitation. Europa Medicophysica. 2008 Oct;44(3):6-8.

[152] Busnel M, Cammoun R, Coulon-Lauture F, Détriché JM, Le Claire G, Lesigne B. The robotized workstation" MASTER" for users with tetraplegia: Description and evaluation. Journal of rehabilitation research and development. 1999 Jul 1;36(3):217-29.

[153] Belpaeme T, Baxter P, Read R, Wood R, Cuayáhuitl H, Kiefer B, Racioppa S, KruijffKorbayová I, Athanasopoulos G, Enescu V, Looije R. Multimodal child-robot interaction: Building social bonds. Journal of Human-Robot Interaction. 2012 Dec 1;1(2).

[154] Csala E, Németh G, Zainko C. Application of the NAO humanoid robot in the treatment of marrow-transplanted children. In2012 IEEE 3rd International Conference on Cognitive Infocommunications (CogInfoCom) 2012 Dec 2 (pp. 655-659). IEEE.

[155] Fasola J, Matarić MJ. A socially assistive robot exercise coach for the elderly. Journal of Human-Robot Interaction. 2013 Jun 18;2(2):32.

[156] Garcia P, Rosen J, Kapoor C, Noakes M, Elbert G, Treat M, Ganous T, Hanson M, Manak J, Hasser C, Rohler D. Trauma Pod: a semiautomated telerobotic surgical system. The International Journal of Medical Robotics and Computer Assisted Surgery. 2009 Jun;5(2):13646.

[157] Wortman TD, Meyer A, Dolghi O, Lehman AC, McCormick RL, Farritor SM, Oleynikov D. Miniature surgical robot for laparoendoscopic single-incision colectomy. Surgical endoscopy. 2012 Mar 1;26(3):727-31..

[158] Cassilly D, Kantor S, Knight LC, Maurer AH, Fisher RS, Semler J, Parkman HP. Gastric 
emptying of a non-digestible solid: assessment with simultaneous SmartPill $\mathrm{pH}$ and pressure capsule, antroduodenal manometry, gastric emptying scintigraphy. Neurogastroenterology \& Motility. 2008 Apr;20(4):311-9.

[159] M. J. Lang, A. D. Greer, and G. R. Sutherland, "Intraoperative robotics: NeuroArm," Intraoperative Imaging, vol. 109, pp. 231-236, 2011.

[160] U. Hagn, R. Konietschke, A. Tobergte et al., "DLR MiroSurge: a versatile system for research in endoscopic telesurgery," International Journal of Computer Assisted Radiology and Surgery, vol. 5, no. 2, pp. 183193, 2010.

[161] Jay S, Litt IF, Durant RH. Compliance with therapeutic regimens. Journal of Adolescent Health Care. 1984 Apr 1;5(2):124-36.

[162] Duncan PW, Horner RD, Reker DM, Samsa GP, Hoenig H, Hamilton B, LaClair BJ, Dudley TK. Adherence to postacute rehabilitation guidelines is associated with functional recovery in stroke. Stroke. 2002 Jan 1;33(1):167-77.

[163] Sluijs EM, Kok GJ, Van der Zee J. Correlates of exercise compliance in physical therapy. Physical therapy. 1993 Nov 1;73(11):771-82.

[164] Ice R. Long-term compliance. Physical Therapy. 1985 Dec 1;65(12):1832-9.

[165] Dishman RK, Ickes W. Self-motivation and adherence to therapeutic exercise. Journal of behavioral medicine. 1981 Dec 1;4(4):421-38.

[166] Loureiro R, Amirabdollahian F, Topping M, Driessen B, Harwin W. Upper limb robot mediated stroke therapy-GENTLE/s approach. Autonomous Robots. 2003 Jul 1;15(1):35-51.

[167] Coote S, Murphy B, Harwin W, Stokes E. The effect of the GENTLE/s robot-mediated therapy system on arm function after stroke. Clinical rehabilitation. 2008 May;22(5):395-405.

[168] ${ }^{1}$ Ravenek KE, Wolfe DL, Hitzig SL. A scoping review of video gaming in rehabilitation. Disability and rehabilitation: Assistive technology. 2016 Aug 17;11(6):445-53.

[169] Betker AL, Szturm T, Moussavi ZK, Nett C. Video game-based exercises for balance rehabilitation: a single-subject design. Archives of physical medicine and rehabilitation. 2006 Aug 1;87(8):1141-9.

[170] Seo K, Kim J, Lee J, Jang S, Ryu H. Serious games for stroke patients: attending to clinical staff's voices. InThe 5th International Congress of International Association of Societies of Design Research 2013 (pp. 1-11).

[171] Burke JW, McNeill M, Charles D, Morrow P, Crosbie J, McDonough S. Serious games for upper limb rehabilitation following stroke. In2009 Conference in Games and Virtual
Worlds for Serious Applications 2009 Mar 23 (pp. 103-110). IEEE.

[172] .Novak D, Nagle A, Keller U, Riener R. Increasing motivation in robot-aided arm rehabilitation with competitive and cooperative gameplay. Journal of neuroengineering and rehabilitation. $2014 \mathrm{Dec} ; 11(1): 64$.

[173] Cappa P, Clerico A, Nov O, Porfiri M. Can force feedback and science learning enhance the effectiveness of neuro-rehabilitation? An experimental study on using a low-cost 3D joystick and a virtual visit to a zoo. PLoS One. 2013 Dec 13;8(12):e83945.

[174] Laut J, Henry E, Nov O, Porfiri M. Development of a mechatronics-based citizen science platform for aquatic environmental monitoring. IEEE/ASME Transactions on Mechatronics. 2013 Nov 14;19(5):1541-51.

[175] Laut J, Cappa F, Nov O, Porfiri M. Increasing patient engagement in rehabilitation exercises using computer-based citizen science. PloS one. 2015 Mar 20;10(3):e0117013.

[176] Saposnik G, Teasell R, Mamdani M, Hall J, McIlroy W, Cheung D, Thorpe KE, Cohen LG, Bayley M. Effectiveness of virtual reality using Wii gaming technology in stroke rehabilitation: a pilot randomized clinical trial and proof of principle. Stroke. 2010 Jul 1;41(7):1477-84.

[177] Han J, Shao L, Xu D, Shotton J. Enhanced computer vision with microsoft kinect sensor: A review. IEEE transactions on cybernetics. 2013 Jun 25;43(5):1318-34.

[178] Kitsunezaki N, Adachi E, Masuda T, Mizusawa JI. KINECT applications for the physical rehabilitation. In2013 IEEE International Symposium on Medical Measurements and Applications (MeMeA) 2013 May 4 (pp.294299).IEEE. 